\title{
Teaching Efficacy in the Classroom: Skill Based Training for Teachers' Empowerment
}

\author{
Mansoureh Karimzadeh ${ }^{1}$, Hadi Salehi ${ }^{2}$, Mohamed Amin Embi ${ }^{3}$, Mehdi Nasiri ${ }^{1} \&$ Mohammad Shojaee $^{2}$ \\ ${ }^{1}$ University of Social Welfare and Rehabilitation Sciences, Tehran, Iran \\ ${ }^{2}$ Faculty of Literature and Humanities, Najafabad Branch, Islamic Azad University, Najafabad, Isfahan, Iran \\ ${ }^{3}$ Faculty of Education, Universiti Kebangsaan Malaysia (UKM), Bangi, Malaysia \\ Correspondence: Mansoureh Karimzadeh, University of Social Welfare and Rehabilitation Sciences, Tehran, Iran. \\ E-mail: mkarimz2000@gmail.com
}

Received: April 24, 2014 Accepted: June 19, 2014 Online Published: July 15, 2014

doi:10.5539/elt.v7n8p106 URL: http://dx.doi.org/10.5539/elt.v7n8p106

\begin{abstract}
This study aims to use an experimental research design to enhance teaching efficacy by social-emotional skills training in teachers. The statistical sample comprised of 68 elementary teachers (grades 4 and 5) with at least 10 years teaching experience and a bachelor's degree who were randomly assigned into control (18 female, 16 male) and experimental (20 female, 14 male) groups. During ten weekly sessions of training the experimental groups learned a set of social-emotional skills (interpersonal-intrapersonal skills). Bar-On social emotional scales (adult version) and a researcher-made questionnaire for teaching efficacy were used to collect the required data. Independent t-tests, mix models of variance, multivariate analyses of variance, and regressions were used to compare the mean of social-emotional intelligence and its components and teaching efficacy differences between and within groups. The results showed that training had a significant effect on increasing social emotional skills and its components of the experimental group teachers. This research also showed a positive correlation between the enhancement of emotional skills and effective teaching. To be most effective, emotional skills training programs need to be applied in the classroom consistently across the curriculum, and teachers` involvement with these skills is needed to promote their social-emotional abilities.
\end{abstract}

Keywords: teacher, emotional intelligence, social emotional skills training, effective teaching

\section{Introduction}

During the past two decades, a global movement has begun by researchers, workers, and policy-makers to study the effective factors in maximizing the efficiency of the educational system (Teddlie \& Reynolds, 2000). They have also focused their attention on educational achievement, school supervision, characteristics of efficient schools in the international level, and special issues in inefficient educational systems. The recent research studies have shown that unwillingness in studying issues related to teaching and education will have harmful consequences. The current reports from sources such as Teaching Standards Department and variation in teachers' abilities and their outcomes show that these results are rather based on empirical knowledge than research-oriented knowledge. Secondly, the studies related to school efficiency show that the variation "within the school borders' effect the variation and differences "between the schools" (Fitz-Gibbon, 1996) and the teacher and learning effects are remarkably far more important than the school effect. Thus, today there is an opportunity for the school efficiency movement to study the classroom and its teachers with the same clarity and concentration. This is evident in the studies related to school efficiency that students' performances are highly significant within the classroom rather than the schools at the international level. This is more related to "efficient schools" than "efficient teachers". In fact, the more the relative effects of the schools in comparison to the teachers' role are considered, the more justifications will be found for such problems; hence, many educational reforms have failed in this regard. Since our interventions within the school borders are based on strict rules, and not focused on learning, they are less effective.

The schooling process is formed with an interactive process among factors such as school, classroom, teacher, student, teaching subject, and learning. Dynamicity and effectiveness versus static state and inefficiency of this process are related to these factors. There are a number of effective factors in the efficient school and efficient 
teacher: general teaching skills (interactive teaching, direct teaching, review and practice), classroom management, behavior management, classroom environment, effective use of homework and advanced thinking and problem-solving skills, teaching special skills and teaching students with special needs (social and emotional skills, self-esteem, training exceptional students, first year education, considering personal differences), teaching special issues (mathematics, information and communication technology), evaluation and professional growth (Teddlie \& Reynolds, 2000). In general, an efficient teacher is one who is able to achieve the desired results from the learning process. If the students would not be able to achieve the desired learning goals, the teacher cannot be an efficient teacher.

Woolfolk (2004) believes that efficient teaching is interconnected with being a successful teacher. A successful teacher is the one who directs, facilitates, and manages the students' learning process. Although in the teaching process, the basic element of learning is the learner himself, the teacher plays a significant role in this process. The authors believe that in this process, even though the professional and academic skills, mastery of course topics, choice of suitable teaching method, and academic motivation play significant roles, the teacher's interpersonal skills (communication skills, empathy, etc.), commitment, motivation and interest in learners make teaching effective (Santrok, 2004).

According to Abraham (1999), there is a close relationship between students' success and higher efficiency among teachers: the greater the students' achievement, the stronger the teachers' feelings toward themselves. This will, however, anticipate their future achievement. Accordingly, learning and teaching are the results of the interaction between the learner and the teacher in a supporting, accepting, and secure environment. Such an environment requires the following terms: positive leaning environment, basic knowledge, meaningful relationships, thinking opportunities, special feedbacks according to the content and feelings, natural knowledge, success in educational and social-emotional intelligence (Duty, 2001).

Bar-On (2006) believes that the social-emotional intelligence consists of a group of skills, talents, and non-cognitive abilities (in five dimensions: interpersonal, intrapersonal, general creation, perseverance in pressure, and adaptation) that increase the personal successful chance to deal with the pressures and environmental requirements. Mayer, Salovey \& Caruso (2000) argue that emotional intelligence is an ability to identify and recognize the concepts and meanings of emotions, and their interrelationships to reason them out and to solve relevant problems. Also, this construct includes the ability to receive emotions, to coordinate different emotions and feelings to understand the information related to emotions, and to take emotions under control. The people's weaknesses in social emotional skills could be related to issues such as physical and physiological health (Sutton \& Wheatley, 2003), aggression (Winters, Clift, \& Dutton, 2004), alcohol consumption (Zins et al, 2000, 2004), depression and anxiety (Zeman, Shipman, \& Suveg, 2002; Silk, Steinberg, $\&$ Morris, 2003).

In addition, much research shows that the effective teaching and the quality of teacher's relationships depend on their social- emotional intelligence (Brackett \& Salovey, 2004; Sutton \& Wheatley, 2003). However, these skills play a central role in the social, personal, and educational life of a person and affect their overall intelligence.

Elias (2006) believes that creating changes in the teachers' behaviors, cognitive, social, and emotional abilities, class and school environment is the initial attempt to involve school for making it more efficient for social-emotional learning programs (SEL). In this case, one of the most reliable associations that supports educational learning and efficient school environments has received the title of 'supportive council' for improving the social- emotional learning (The Collaboration to Advance Social and Emotional Learning, CASEL). CASEL confirms the existence of difference in teachers' behavior, class atmosphere, and school environments. Therefore, it suggests two activities for the efficiency of SEL programs. These two activities are as below:

1) Creating secure and supportive environment and good management show the atmosphere of class is in disciplined process.

2) Creating an environment that achieves suitable outcomes for growth in teaching social emotional abilities (Elias \& Arnold, 2006).

On the other hand, Duty (2001), for integrating and growing the emotional and educational learning in the classroom, suggests that the first step create an environment where the students feel secure, open, and positive. Teachers with creating the "no fear" program (the environment in which safety, choices, respect, multiple intelligence, motivation, relevant learning, and emotional intelligence of students are considered) can help to facilitate this environment. 
Although various studies have found the relationship between emotional intelligence and job satisfaction and efficient training, Hoberman and Mailick (1994) believe that the school principals rarely have the awareness, readiness or even the necessary desire for achieving these abilities. Meanwhile, professional training does not include the application of emotions for developing such skills (Abraham, 1999). Moreover, the majority of social-emotional skills training programs, attempt to increase and improve students' social emotional and educational performances (Newsome, Day, \& Catano, 2000; O’Connor \& Little, 2003).

Today for being successful, schools and teachers need programs that focus not only on students to increase their social emotional skill but also on the school efficiency movement (Reynolds \& Sullivan, 1999). The teachers, employees, and the human resources experience a wide range of negative and positive emotions during teaching and interacting with students. The essence of their job is that they have to face with their own emotions as they face with their students', parents' and their colleagues' emotions. The teachers who have problems in managing their emotions (especially in the class) will have students who experience more negative emotions (Burns, 2000; Travers \& Cooper, 1993).

In one study, more than 30 percent of English teachers felt their job to be stressful (Travers \& Cooper, 1993). In fact, stress and weak management of emotions are considered to be the main reason why many teachers are not satisfied with their jobs and simply quit. Also, this issue could be the reason for the lack of teachers' interest and its negative applications in learning environments at school and an alarm for the fulfillment of the educational objectives. Weakness in social-emotional learning is one of the origins of such problems and the best alternative in this situation is to equip teachers with the necessary training in more advanced emotional and social issues

Studies show that teaching the management of emotions and their usage in cognitive and communication skills will lead to a better and more acceptable interpersonal performance (Greenberg \& Kusche, 1993). Moreover, teaching emotional skills to teachers can not only develop the abilities in determining his or other's emotions , help them analyze the verbal and nonverbal communications, be successful in their interactions with parents and principals and enhance effective teaching but also help to choose a suitable time and pay enough attention to the growth of emotional awareness in students in a stable, supportive, and learning environment -where positive social interactions, active engagement, and educational achievement take place.

There are a number of studies which have focused on the effects of social emotional skills training (Hawkins, Farrington, \& Catalano, 1998; Elias \& Tobias, 1996; Elias et al., 1997), with a focus on students' self-awareness, problem solving ,and decision-making skills to result in better social emotional performance (Durlak, 2005; Burns, 2000; Duty, 2001). The fact is that many teachers admit that both the teachers and their students have a poor background and strategies in relation to social- emotional capabilities (Teddlie \& Reynolds, 2000; Burn, 2000). One-day workshops have not enabled the teachers to acquire the components of effective learning. Accordingly, the necessity of teaching social emotional skills to teachers is quite self-evident. It is expected that helping teachers acquire social emotional skills is effective for efficient communication, more effective teaching in the classroom, stress and conflict management, and keeping the positive environment in the class.

The present research is theoretically based on the Bar-On's theory. The content of the social-emotional training programs for teachers are adjusted in two interpersonal dimensions (self-awareness, emotional management, stress management, decision making and problem solving, ego term, self-confidence and goal orientation)and intrapersonal dimension (communication skills (verbal and non-verbal, listening skills), self-expression, sympathy, self-revelation , and ending up the disputes. Also, these assumptions are examined in the main questions of this research. To conduct this research, the following research hypotheses were constructed:

1) Educational interventions (teaching social and emotional skills) lead to the enhancement of the social emotional intelligence of teachers.

2) Teaching social emotional skills influences the improvement of effective teaching.

\section{Methodology}

This research is an experimental study and a type of applied research. A pre-test/post-test design with time intervals was used in this study. The research sample was chosen from among volunteer teachers in fourth and fifth grades of primary school who were in their training period at Tehran, Iran. They all had at least a bachelor's degree and had experienced more than 10 years of teaching practice ( 75 persons). In the first session, after performing the pre-tests of the Bar-On' Social Emotional Test and effective teaching test, the participants, were randomly divided into experimental and control groups. Seven persons who were not participating in the training sessions, were excluded and the final sample teachers included 68 participants in control (18 women and 16 men) 
and experimental groups (20 women and 14 men).The learning skills for the teachers programs (social emotional training skill) were taken from the Bar-On's theoretical model (1997), and the Golman's suggested principles (1998) presented in the EDU or program, SEL social emotional learning program (2003), some of the Chris' concepts and life skills program training (2001) and UNICEF's life skills training program (2000).

\section{Instruments}

\subsection{Bar-on Social-Emotional Questionnaire (Adults)}

This questionnaire consists of 133 items and a general score (General Social Emotional Intelligence) in five dimensions and 15 subscales and is applicable for the people with 16 years of age and older that have basic literacy skills. Samoei (2003) had standardized this test and reduced its items to 90 in fifteen components. She had obtained the validity of the subscales, using correlation coefficient between the general score of each component and the overall score of the test (more than 0.70). In the current research, the validity of the interpersonal factor 4/0, intrapersonal, 89/0, adaptation, 79/0, the general mood 55/0 and stress management, $78 / 0$ and general social emotional, 0/93 were obtained.

\subsection{Effective teaching Questionnaire}

To develop our research questionnaire, we used Woolfolk (2004), Santork's (2004) efficient teaching factors, and Parsons, Hinson, and Browns' (2001) effective teaching factors. In total, 110 items were designed. Using the contents validity and the experts' views, questions were reduced to 71 items; then 37 teachers with more than ten years of experience filled out the questionnaires. With the omission of the ambiguous items and reducing the correlation coefficient, only 60 items were included using Likert Scale: $(1,2=$ null), $(3,4=$ very little), $(5,6=$ somehow), $(8,9=$ very much). A questionnaire comprising 60 items was distributed among 220 teachers. In the exploration factors analysis and with the omission of the items that were not included in any factor and have fewer coefficients than 0.3 , thirty-one items were left. Using factor analysis, the 31 items were included in factor 7.

The correlation between items was $82 / 0$ to $94 / 0$, and the test sample Adequacy was $894 / 0$ respectively. In addition, the seven factors were able to explain $64 \%$ of the variance. The validity of this questionnaire is reported with counting the Chronbach's Alpha for overall score is almost 0.93. The reliability of the questionnaire by calculating Cronbach's Alpha for each subscale and total score between $6 / 0$ to $8 / 0$, for total score $93 / 0$ was reported.

\section{The Program of (EIT)}

Teacher social emotional skills training implemented for ten sessions (once a week). Each session was implemented for 2 hours. This program performed in two domains:

Interpersonal: (self-awareness, feeling management, stress management, self-concept, self-confidence),

Intrapersonal: (verbal-nonverbal relationship, listening, empathy, assertiveness, decision making, problem solving, conflict solution).

\section{Findings}

To test the hypothesis of this research, a mixed model analysis of variance, multivariate analysis of variance, simple regression, stepwise regression, and the t- test for independent samples were used. Equality of variance assumption was examined by Levine's test. Levine's test was not significant in any of the tests mentioned. Therefore, variances were equal.

In the mixed design, equality of covariance was measured by Mauchlys Test of Sphericity if the Mauchlys Test was significant. To report analyses, Greenhouse-Geisser test was used. In the multivariate analysis of variance tests, equal variances were studied by Levine test. This test showed that variances are equal.

To evaluate differences between groups of subjects in general education teachers, social emotional intelligence, independent groups' $t$-test indicated that the subjects in groups had no significant difference in pre-test in the overall emotional intelligence.

In order to examine the significant difference between teacher's subject groups of the social emotional intelligence before test, the independent test indicated that the subjects groups showed no significant difference in pre-test in the total emotional intelligence. Moreover, the results of the multivariate and univariate analysis of variance tests indicated that the subjects groups had no significant differences in any of the emotional intelligence components. 
Table 1. Between subject effects of social- emotional intelligence (EI) and its components (before training)

\begin{tabular}{lllllll}
\hline Variable & Source & Mean & SD & N & F & Sig \\
\hline \multirow{2}{*}{ General mood } & Control & 4.001 & 0.532 & 34 & \multirow{2}{*}{0.4} & \multirow{2}{*}{$0 / 67$} \\
& Treatment & 4.005 & 0.563 & 34 & & \\
Adjustment skill & Control & 3.48 & 0.394 & 34 & \multirow{2}{*}{1.56} & $0 / 06$ \\
& Treatment & 3.46 & 0.373 & 34 & & \\
Interpersonal skill & Control & 3.90 & 0.454 & 34 & \multirow{2}{*}{0.15} & $0 / 32$ \\
& Treatment & 4.04 & 0.288 & 34 & & \\
Intrapersonal skill & Control & 3.47 & 0.375 & 34 & 0.865 & $0 / 43$ \\
& Treatment & 3.53 & 0.374 & 34 & & \\
Stress management & Control & 3.59 & 0.395 & 34 & 0.78 & $0 / 4$ \\
& Treatment & 3.62 & 0.462 & 34 & & \\
Total EI skill & Control & 3.71 & 0.355 & 34 & \multirow{2}{*}{0.215} & $0 / 6$ \\
& Treatment & 3.74 & 0.310 & 34 & & \\
\hline
\end{tabular}

In order to test the operating effectiveness testing (teaching social - emotional skills) g.the different scores for the total and social emotional intelligence components (difference between the pre-test and post-test scores) were calculated for all subjects, then difference mean scores were analyzed.

In the analysis of the differences in total social emotional skills (after training), independent t- test indicated significant differences between the subjects groups in the total social- emotional skills .

In addition, multivariate and univariate analysis of variance indicated that (after training), the experimental group compared to the control group has significant increase in total social emotional skills and its components (see Table, 2).

Table 2. Between subject effects of social- emotional intelligence (EI) and its components (after training)

\begin{tabular}{|c|c|c|c|c|c|c|}
\hline Variable & Source & Mean & SD & $\mathrm{N}$ & $\mathrm{F}$ & Sig \\
\hline \multirow{2}{*}{ General mood } & Control & -0.157 & 0.37 & 34 & \multirow{2}{*}{20.69} & \multirow{2}{*}{$0 / 001$} \\
\hline & Treatment & 0.21 & 0.28 & 34 & & \\
\hline \multirow{2}{*}{ Adjustment skill } & Control & -0.14 & 0.39 & 34 & \multirow{2}{*}{17.63} & \multirow{2}{*}{$0 / 001$} \\
\hline & Treatment & 0.62 & 0.42 & 34 & & \\
\hline \multirow{2}{*}{ Interpersonal skill } & Control & 0.04 & 0.33 & 34 & \multirow{2}{*}{58.94} & \multirow{2}{*}{$0 / 001$} \\
\hline & Treatment & 0.62 & 0.42 & 34 & & \\
\hline \multirow{2}{*}{ Intrapersonal skill } & Control & -0.03 & 0.42 & 34 & \multirow{2}{*}{38.38} & \multirow{2}{*}{$0 / 001$} \\
\hline & Treatment & 0.34 & 0.26 & 34 & & \\
\hline \multirow{2}{*}{ Stress management } & Control & 0.08 & 0.42 & 34 & \multirow{2}{*}{18.74} & \multirow{2}{*}{$0 / 001$} \\
\hline & Treatment & 0.053 & 0.46 & 34 & & \\
\hline \multirow{2}{*}{ Total EI skill } & Control & -0.04 & 0.25 & 34 & \multirow{2}{*}{68.28} & \multirow{2}{*}{$0 / 001$} \\
\hline & Treatment & 0.46 & 0.26 & 34 & & \\
\hline
\end{tabular}

At follow-up, a mixed model analysis of variance indicated the experimental group compared to the control group had no significant reduction in total social- emotional skills and its components (see Tables $2 \& 3$ ). 
Table 3. Mean (SD) social and emotional intelligence score and its components (post test \&follow up)

\begin{tabular}{llllllll}
\hline \multirow{2}{*}{ Group Scale } & & \multicolumn{7}{l}{ Treatment } & \multicolumn{2}{c}{ Control } \\
\cline { 3 - 8 } & & Mean & SD & $\mathrm{N}$ & Mean & SD & $\mathrm{N}$ \\
\hline \multirow{2}{*}{ Interpersonal skill } & After training & 0.61 & 0.42 & 34 & 0.044 & 0.3 & 34 \\
& Follow up & 0.58 & 0.38 & 34 & 0.038 & 0.25 & 34 \\
Intrapersonal skill & After training & 0.34 & 0.26 & 34 & -0.03 & 0.42 & 34 \\
& Follow up & 0.32 & 0.25 & 34 & -0.02 & 0.31 & 34 \\
Stress management skill & After training & 0.53 & 0.46 & 34 & 0.08 & 0.42 & 34 \\
& Follow up & 0.53 & 0.43 & 34 & 0.07 & 0.37 & 34 \\
General mood & After training & 0.21 & 0.28 & 34 & -0.157 & 0.37 & 34 \\
& Follow up & 0.21 & 0.25 & 34 & -0.12 & 0.34 & 34 \\
Adjustment skill & After training & 0.62 & 0.42 & 34 & -0.14 & 0.39 & 34 \\
\multirow{3}{*}{ Total EI skill } & Follow up & 0.6 & 0.41 & 34 & -0.11 & 0.32 & 34 \\
& After training & 0.46 & 0.25 & 34 & -0.04 & 0.24 & 34 \\
& Follow up & 0.48 & 0.24 & 34 & -0.029 & 0.18 & 34 \\
\hline
\end{tabular}

Table 4. Between subject effects of social- emotional intelligence (EI) and its components (follow up stage)

\begin{tabular}{|c|c|c|c|c|c|c|}
\hline Variables & Source & SS & df & MS & $\bar{F}$ & Sig \\
\hline \multirow{2}{*}{ Interpersonal skill } & Group & 4.38 & 1 & 4.38 & \multirow{2}{*}{21.07} & \multirow{2}{*}{0.01} \\
\hline & Error & 19.39 & 66 & 0.203 & & \\
\hline \multirow{2}{*}{ Intrapersonal skill } & Group & 18.48 & 1 & 18.48 & \multirow{2}{*}{63.35} & \multirow{2}{*}{0.01} \\
\hline & Error & 19.25 & 66 & 0.292 & & \\
\hline \multirow{2}{*}{ Stress management skill } & Group & 6.96 & 1 & 6.96 & \multirow{2}{*}{19.403} & \multirow{2}{*}{0.01} \\
\hline & Error & 23.7 & 66 & 0.36 & & \\
\hline \multirow{2}{*}{ General mood } & Group & 4.134 & 1 & 4.134 & \multirow{2}{*}{21.07} & \multirow{2}{*}{0.01} \\
\hline & Error & 12.94 & 66 & 0.36 & & \\
\hline \multirow{2}{*}{ Adjustment skill } & Group & 10.45 & 1 & 1.45 & \multirow{2}{*}{39.47} & \multirow{2}{*}{0.01} \\
\hline & Error & 17.48 & 66 & 0.27 & & \\
\hline \multirow{2}{*}{ Total EI skill } & Group & 8.178 & 1 & 8.178 & \multirow{2}{*}{76.06} & \multirow{2}{*}{0.01} \\
\hline & Error & 7.096 & 66 & 0.108 & & \\
\hline
\end{tabular}

The results of the analysis indicated that social-emotional skills training of teachers have significant lasting impacts, so the first research hypothesis was confirmed.

Examination of the Second Hypothesis: The independent $t$-test showed no significant differences between experimental groups in effective teaching in the pre-test level (see Table 5).

After the social-emotional training course, independent t-test indicated that there are significant differences (between the pre-test and post-test scores) between the subjects groups in the effective teaching.

In addition, within subjects effects test showed no significant decrease in the effective teaching in follow up stage within subjects groups. However, between subjects effects test can show a significant difference between the groups in follow up stage. In addition, the experimental group compared to the control group has a significant increase in total effective teaching. 
Table 5. Descriptive indicators and independent $t$ test tests for effective teaching (before, after training follow up)

\begin{tabular}{lllllll}
\hline Stage & Group & $\mathrm{M}$ & $\mathrm{Sd}$ & $\mathrm{N}$ & $\mathrm{F}$ & Sig \\
\hline \multirow{2}{*}{ Before } & Control & 6.99 & 0.81 & 34 & \multirow{2}{*}{0.194} & \multirow{2}{*}{0.66} \\
& Treatment & 7.074 & 0.61 & 34 & & \\
\multirow{3}{*}{ After } & Control & 0.091 & 0.61 & 34 & 4.4 & 0.01 \\
& Treatment & 0.77 & 0.64 & 34 & & \\
\multirow{2}{*}{ Follow up } & Control & 0.07 & 0.61 & 34 & \multirow{2}{*}{20.53} & 0.01 \\
& Treatment & 0.77 & 0.65 & 34 & & \\
\hline
\end{tabular}

To examine the relationship between social-emotional intelligence and its components with the effective teaching (before the test), the Pearson Correlation showed that social emotional intelligence and the teacher effective teaching had a significant correlation $(\mathrm{r}=0.254, \mathrm{p}<0.001)$._Also, effective teaching with interpersonal component $(r=0.414, p<0.001)$, adjustment $(r=0.134, p<0.001)$ and a stress management $(r=0.282, p<0.001)$ were significantly correlated (see Table 6).

Table 6. Pearson correlation between effective teaching and emotional intelligence (before training)

\begin{tabular}{lllllll}
\hline Variables & $\begin{array}{l}\text { General } \\
\text { mood skill }\end{array}$ & $\begin{array}{l}\text { Stress } \\
\text { management skill }\end{array}$ & $\begin{array}{l}\text { Adjustment } \\
\text { skill }\end{array}$ & $\begin{array}{l}\text { Intrapersonal } \\
\text { skill }\end{array}$ & $\begin{array}{l}\text { Interpersonal } \\
\text { skill }\end{array}$ & $\begin{array}{l}\text { Total } \\
\text { EI skill }\end{array}$ \\
\hline $\begin{array}{l}\text { General mood skill } \\
\text { Stress }\end{array}$ & & & & & \\
management skill & $0.213^{*}$ & & & & \\
Adjustment skill & $0.214^{*}$ & $0.2^{*}$ & & & \\
Intrapersonal skill & $0.25^{*}$ & $0.26^{*}$ & $0.23^{*}$ & & \\
Interpersonal skill & 0.134 & 0.196 & $0.285^{*}$ & $0.27^{*}$ & & \\
Total EI skill & $0.688^{* *}$ & $0.82^{*}$ & $0.82^{*}$ & $0.77^{*}$ & $0.59^{*}$ & \\
Effective teaching & 0.029 & $0.282^{*}$ & $0.34^{*}$ & -0.018 & $0.414^{*}$ & $0.254^{*}$ \\
\hline $\mathrm{p}<0.01=* * \mathrm{p}<0.05=*$ & & & & &
\end{tabular}

Moreover, the results of the simple regression showed that the teachers' social- emotional intelligence could predict some parts of their effective teaching in experimental group (0.23), and control group (0.19); this explains the changes in the social emotional intelligence of the teachers through their trainings. Before the training, from the social emotional intelligence components, stress management, adjustment and interpersonal relationship with effective teaching had positive correlation. After inserting the positively correlated variables with effective teaching in the step by step regression, the results showed that only interpersonal component can explain the effective teaching $(\mathrm{R} 2=0.154)$.

Table 7. Simple regression analysis of emotional intelligence to predict effective teaching

\begin{tabular}{|c|c|c|c|c|c|c|c|c|c|c|}
\hline Stage & & Group & Model & SS & MS & df & $\mathrm{F}$ & Sig & $\mathrm{R}$ & $\mathrm{R} 2$ \\
\hline \multirow{6}{*}{ Before } & \multirow{4}{*}{ Total EI skill } & \multirow{2}{*}{ Control } & Regression & 2.928 & 2.928 & 1 & \multirow{2}{*}{7.533} & \multirow{2}{*}{0.01} & \multirow{2}{*}{0.437} & \multirow{2}{*}{0.191} \\
\hline & & & Residual & 12.44 & 389 & 32 & & & & \\
\hline & & \multirow{2}{*}{ Treatment } & Regression & 3.21 & 3.21 & 1 & \multirow{2}{*}{8.56} & \multirow{2}{*}{0.01} & \multirow{2}{*}{0.483} & \multirow{2}{*}{0.232} \\
\hline & & & Residual & 8.92 & 0.28 & 32 & & & & \\
\hline & \multirow{2}{*}{ Intrapersonal } & \multirow{2}{*}{ Treatment } & Regression & 4.37 & 4.37 & 1 & \multirow{2}{*}{11.995} & \multirow{2}{*}{0.001} & \multirow{2}{*}{0.392} & \multirow{2}{*}{0.1543} \\
\hline & & & Residual & 23.97 & 0.363 & 66 & & & & \\
\hline \multirow{2}{*}{$\begin{array}{l}\text { After } \\
\text { training }\end{array}$} & \multirow{2}{*}{ Total EI skill } & \multirow{2}{*}{ Treatment } & Regression & 1.822 & 1.822 & 1 & \multirow{2}{*}{4.827} & \multirow{2}{*}{0.03} & \multirow{2}{*}{0.392} & \multirow{2}{*}{0.131} \\
\hline & & & Residual & 384.16 & 12.077 & 32 & & & & \\
\hline
\end{tabular}


Different scores of the effective teaching had general emotional intelligence (pre-test from post-test subtraction was used) to investigate the relationship between teachers' social-emotional intelligence and their effective teaching improvement. The result of simple regression test showed that the teachers' improvement in the socialemotional intelligence had a positive relationship with an increase in the effective teaching. Thirteen percent of the effective teaching difference scores can be explained with the difference scores of the social- emotional intelligence (see Table 7).

\section{Discussion and Conclusion}

All the evidence obtained from the studies related to the effective school showed that in assigning the children's performance at school, the classrooms are more important (Teddlie \& Reynolds, 2000). On the other hand, other similar studies show that the teacher and learning effects are far more significant than the school effect. It seems necessary that Educational System especially teachers benefit from all scientific and practical guidance levels to have effective teaching such as social emotional skills. The authors in this area believe that social emotional skills could be learned and improved through training and practice at any age.

The results of the current research show that effective skill learning leads to improvement in the socialemotional intelligence and its components and efficient teaching. On the other hand, this effectiveness has been maintained after four months. This latter point clearly shows that the results of the current study are concurrent with other relevant researches (Brackett, Mayer, \& Warner, 2004).

The researchers interested in the analysis of the teachers' efficiency and performance evaluation area show that efficient teachers are "warm, supportive, empathetic and have positive self-concept._They are capable of creating satisfying human communication, and their classrooms are open, supportive and friendly (Cherniss, 2001).

The ability to manage emotions in oneself and others is a valuable skill for teachers. Teachers who can manage their own emotions and those of their students can have effective and friendly classes, where there are few disturbances and distractions. Moreover, the current research emphasizes the positive and significant relationship between teachers' social emotional intelligence and their effective teaching. The results also showed that teachers' social emotional skills improvement is related to improving their teaching effectively.

According to Burns (2000), effective teachers can be distinguished from ineffective teachers by the following characteristics:

Technological skills education results in flexibility in teaching styles, the ability to empathize, sensitivity to students with special needs, a laudatory attitude and encouragement, self- confidence and emotional adjustment, warm acceptance by others, focus on teaching children, the ability to be with other people instead of being separate from others, positive belief in the ability to solve problems, reality flexibility and independence, humor and justice, willingness and motivation to listen, and caring for students.

Most of the above traits (flexibility, empathy, acceptance, trust and consistency, a belief in the ability and self-sufficiency of others, reality flexibility \& listening) were among the main factors in social-emotional skills which different approaches consider as interpersonal. Therefore, it is expected that improving social emotional intelligence through skill learning enhances effective teaching at schools. Reaching such a conclusion requires a well-developed theory which is adaptable to the particular culture of the teachers. Thus teachers with a good training and enough support must take the responsibility for teaching. This is, however, required when we consider school-oriented programs with emphasis on certain abilities.

\section{References}

Abraham, R. (1999). Emotional intelligence in organizations: A conceptualization. Genetic, social and general psychology monographs. Human Relations, 125, 209-225.

Bar-On, R. (1997). Bar-On Emotional Quotient Inventory: User's Manual. Multi-Health Systems, Inc., Toronto.

Bar-On, R. (2006). The Bar-On model of emotional social intelligence (ESI). University of Texas Medical Branch Psicothema, 18, supl., 13-25.

Brackett, M. A., Mayer, J. D., \& Warner, R. M. (2004). Emotional intelligence and its relation to everyday behaviour. Personality and Individual Differences, 36, 1387-1402.

Brackett, M. A., \& Salovey, P. (2004). Measuring emotional intelligence as a mental ability with the Mayer-Salovey-Caruso Emotional Intelligence Test. In G. intelligent. Rondebosch, South Africa: Heinemann.

Burns, R. (2000). We know how, what's stopping us: Generating effective teaching and learning. Education 
Journal, 28(2), 63-83.

Cherniss, C. (2001). Emotional intelligence and organizational effectiveness. In C. Cherniss, \& D. Goleman (Eds.), The emotionally intelligent workplace. San Francisco: Jossey-Bass.

Collaborative for Academic, Social and Emotional Learning. (2003). Safe and sound: An Educational leader's guide to evidence-based social and emotional learning programs. Retrieved October 1, 2012, from http://www.casel.org

Collaborative for Academic, Social, and Emotional Learning (CASEL). (2007). Safe and sound: How evidence-based sel programs work to produce greater student success in school and life. American Journal of psychiatry, 144, 133. Retrieved from http://www.casel.org

Collaborative for Academic, Social and Emotional Learning (CASEL). (2003). Promoting and youth violence prevention, National center for mental health. Retrieved from http://www.casel.org

Duty, G. (2001). Fostering emotional intelligence in $K-8$ students. Simple strategies and ready-to-use Activities. CoRwin-Press INC. California.

Durlak, J. A., \& Weissberh, R. P. (2005). A major meta-analysis of positive youth development programs. Presentation at the Annual Meeting of the American Psychological Association, Washington, DC.

Elias, M. J., \& Tobias, S. E. (1996). Social problem solving interventions in the schools. New York: Guilford Press.

Elias, M. J. (2006). Practice RUBRIC for school wide sel implementation. New York. Psychology Press.

Elias, M. J., \& Arnold, H. (2006). The educator's guide to emotional intelligence and academic achievement, social emotional learning in the classroom. New York: Corwin-Press, Guilford.

Elias, M. J., Zins, J. E., Weissberg, R. P., Frey, K. S., Greenberg, M. T., Haynes, N. M., ... Shriver, T. P. (1997). Promoting social and emotional learning: Guidelines for educators. Alexandria, VA: Association for Supervision and Curriculum Development.

Fitz-Gibbon, C. T. (1996). Monitoring education: Indicators, quality and effectiveness. London: Cassell.

Greenberg, M. T., \& Kusche, C. A. (1993). Prompting social and emotional development in deaf children. The PATHS project: University of Washington-Gardner, H. Frames of mind: The theory of multiple intelligence. New York: Basic Books.

Hoberman, S., \& Mailick, S. (Ed.). (1994). Professional education in the United States. Praeger, Westport, CT.

Hawkins, J. D., Farrington, D. P., \& Catalano, R. F. (1998). Reducing violence through the schools. In D. S. Eliot, B. A. Hamburg, \& K. R. Williams (Eds.), Violence in American Schools: A new perspective. Cambridge: Cambridge University Press.

Mayer, J. D., Salovay, P., \& Caruso, D. (2000). Models of emotional intelligence. In R. J. Sternberg (Ed.), Handbook of intelligence (pp. 396-420). Cambridge. UK: Cambridge University press.

Mayer, J. D., Salovey, P., \& Caruso, D. (2004). Emotional intelligence: Theory, findings and implications. Psychological Inquiry, 15, 197-215.

Newsome, S., Day, A. L., \& Catano, V. M. (2000). Assessing the predictive validity of emotional intelligence. Personality and individual differences, 29, 1005-1016.

O’Connor, R. M., \& Little, I. S. (2003). Revisiting the predicative validity of emotional intelligence: Self-report versus ability-based measures. Personality and Individual Differences, 35, 1893-1902.

Parsons, R. D., Hinson, L. S., \& Brown, S. D. (2001). Educational Psychology, a practitioner-researcher model of teaching. West Chester University, Wadsworth.

Reynolds, D., \& Sullivan, M. (1999). The effective teaching of mathematics: A review of research. School Leadership and Management, 19(3), 273-283.

Santrock, J. W. (2004). Educational psychology (2nd ed.). Texas, Dallas: McGraw Hill.

Silk, J. S., Steinberg, I., \& Morris, A. S. (2003). Adolescents' emotion regulation in daily life: Links to depressive symptoms and problem behaviors. Child Development, 74, 1869-1880.

Sutton, R. E., \& Wheatley, K. F. (2003). Teachers' emotions and teaching: A review of the literature and directions for future research. Educational Psychology Review, 15, 327-358. 
Teddlie, C., \& Reynolds, D. (2000). The international handbook of school effectiveness research. London: Falmer.

Travers, C. J., \& Cooper, C. L. (1993). Mental health, job satisfaction and occupational stress among UK teachers. Work and Stress, 7, 203-219.

Winters, J., Clift, R. J. W., \& Dutton, D. G. (2004). An exploratory study of emotional intelligence and domestic abuse. Journal of Family Violence, 19, 255-267.

Woolfolk, A. (2004). Educational psychology (9th ed.). The Ohio State University.

Zins, J. E., Elias, M. J., Greenberg, M. T., \& Kline Pruett, M. (2000). Issues in the implementation of prevention programs [Special Issue]. Journal of Educational and Psychological Consultation, 11(1), 1-2.

Zeman, J., Shipman, K., \& Suveg, C. (2002). Anger and sadness regulation: Predictions to internalizing and externalizing symptoms in children. Journal of Clinical Child and Adolescent Psychology, 31, 393-398.

Zins, J. E., Bloodworth, M. R. Weissberg, R. P., \& Walberg, R. P. (2004). The foundations of social and emotional learning. In J. E. Zins, R. P. Weissberg, M. C. Wang, \& R. P. Walberg (Eds.), Building academic success on social and emotional learning. Teachers college press.

\section{Copyrights}

Copyright for this article is retained by the author(s), with first publication rights granted to the journal.

This is an open-access article distributed under the terms and conditions of the Creative Commons Attribution license (http://creativecommons.org/licenses/by/3.0/). 